\title{
Covid-19 vs. Spanish Flu
}

\author{
Essam A Abo El Magd* and Mai E AbuElmagd \\ Department of Otolaryngology, Aswan University, Egypt \\ *Corresponding author: Essam A Abo El Magd, Department of Otolaryngology, Aswan Faculty of Medicine, Aswan University, Aswan, \\ Egypt
}

\section{Short Communication}

CHistory does not repeat itself. Though every single historical moment is distinct, parallels can be drawn between different historical events. Even though history does not teach us what to do, it can inspire us to act. Revising the 1918 influenza pandemic is an opportunity to consider the current coronavirus (COVID-19) crisis from a different perspective. Influenza and coronavirus share basic similarities in the way they are transmitted via respiratory droplets and contact surfaces. Descriptions of H1N1 influenza patients in 1918-19 resemble the respiratory failure of COVID-19 sufferers a century later. Current discussions about holding back social distancing measures and opening the country frequently refer to "waves" of disease that characterized the dramatic mortality of H1N1 influenza in three major peaks in 1918-19. As COVID-19 rates begin to stabilize in some parts of the U.S., people today are nervously eyeing the "second wave" of influenza that came in autumn 1918, that pandemic's deadliest period.The 1918 influenza pandemic took place during the First World War with three successive waves: the first in the spring of 1918, the second - and most lethal, responsible for $90 \%$ of deaths - in the autumn of 1918 , and a final one from the winter of 1918 to the spring of 1919. By the end of it, more than half of the world's population had been infected. Estimations on mortality, showed a broad spectrum ranging from 2.5 to $5 \%$ of the world's population, which translates to between 50 and 100 million deaths. The pandemic was, therefore, five to ten times deadlier than the First World War.

Waves evoke predictability, however, and COVID-19 has been hard to predict. Despite the lessons drawn from past influenza outbreaks, how pandemic influenza struck in 1918 is not an exact template for what can happen with COVID-19 in the upcoming months [1].The 2020 coronavirus and 1918 Spanish influenza pandemics share many similarities, but they also diverge on some points. Here we empathize some of those points. According to Deutsche Bank, a major difference between Spanish flu and COVID-19 is the age distribution of fatalities. For COVID-19, the elderly has been hit the worst. For the Spanish flu of 1918, the younger population were severely affected. The death rate from pneumonia and influenza that year among the middleaged population in the United States was more than 50\% higher than that for the older population. Back to COVID-19, the overall mortality rate measured by weekly new deaths and weekly new cases is around one-third of the level observed in the second half of April which shows a decline in the current wave [2].Over 500 million people, or one-third of the world's population, became infected with the 1918 Spanish flu. According to the Centers for Disease Control and Prevention, approximately 50 million people died worldwide, with about 675,000 deaths occurring in the US. They added that during the pandemic, mortality was high in three categories of people: younger than 5 years old, 20-40 years old, and 65 years and older. The high mortality in healthy people, including those in the 20-40-year age group, was a unique feature of this pandemic. With no vaccine to protect against it and no antibiotics to treat secondary bacterial infections that can be associated with it, controlling the disease worldwide were limited to nonpharmaceutical interventions.COVID-19, the disease caused by the virus SARS-CoV-2, has already proved extremely infectious. According to Johns Hopkins University's Center for Systems Science and Engineering, it had approximately infected 13.1 million people globally and more than 3.4 million in the U.S. The disease had killed at least 573,664 lives worldwide and 135,615 in the U.S.As for Symptomatology, for both COVID-19 and flu, one day or more can pass between a person becoming infected and when he or she starts to experience illness symptoms. However, if a person has COVID-19, it usually takes longer to develop symptoms than if they had flu. For the flu, a person develops symptoms anywhere from 1 to 4 days after infection but for COVID-19, symptoms can appear as 
early as 2 days after infection or as late as 14 days after infection, and the time range can vary [3].

Being firstly identified in the Chinese city of Wuhan, some have labeled COVID-19 the 'Chinese virus'. Stigmatizing a group or a nation for its alleged responsibility in a calamity is not a new trend. Take the misnomer of the 'Spanish Flu': unlike most of the countries at war at the time, where censorship was extreme and newspapers were initially not allowed to report on the disease, the Spanish press firstly covered the spread of the virus, creating false assumptions that the epidemic originated in Spain.Many other nicknames were given to the pandemic based on nationality or race, for example: 'Spanish Lady', 'French Flu', 'Naples Soldier', 'War Plague', 'Black Man's Disease', 'German Plague', or even the 'Turco-Germanic bacterium criminal enterprise'.War censorship and propaganda also had adverse effects on efforts to mitigate the pandemic. By attempting to censor information on the seriousness of the situation, many belligerent countries most certainly hindered public health efforts to stem the pandemic. Many people did not understand how the flu, an ordinarily mild illness, could cause so many deaths. Some believed their government was lying and trying to hide the return of typhus, cholera, or a so-called 'pneumonic plague'. In Germany, some people accused the government of using a fake pathogen as a pretext to hide the deaths that were caused by malnutrition and exhaustion according to them.The lives lost during that old pandemic teach us that transparent information is essential at all times(Figure 1). To follow public health measures, the population needs to trust the authorities. In 1918, after four years of conflict and propaganda, that trust was broken. This is even more true in 2020. Mistrust of information from health authorities is still a challenge. Modern means of communication and the digital social networks make it even harder. Undocumented claims, false information, conspiracy theories, and dangerous conclusions can spread as quickly as viruses $[4,5]$.

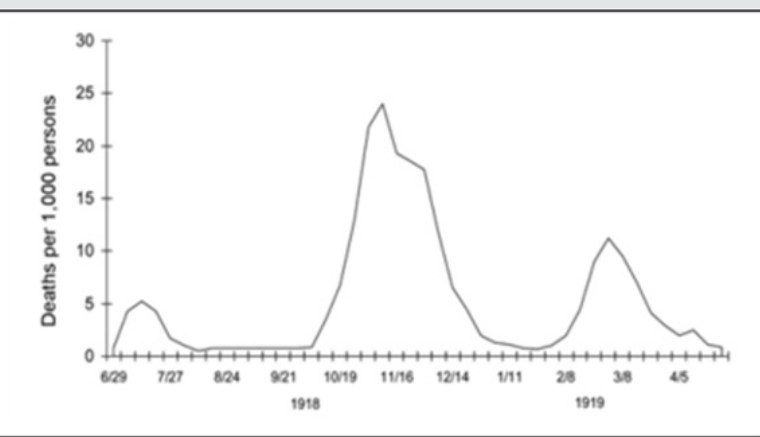

Figure 1: Three waves of death during the pandemic: weekly combined influenza and pneumonia mortality, United Kingdom, 1918-1919. The waves were broadly the same globally[5].

\section{Conflict of Interest: None declared.}

\section{References}

1. Mari Webel, Megan Culler F (2020) Compare the flu pandemic of 1918 and COVID-19 with caution the past is not a prediction.

2. Quentin Fottrell (2020) Here's one 'remarkable' difference between COVID-19 and the 1918 Spanish flu.

3. (2020) Similarities and Differences between Flu and COVID-19.

4. (2020) From the 'Spanish Flu' to COVID-19: lessons from the 1918 pandemic and First World War.

5. Taubenberger JK, Morens DM (2006) 1918 Influenza: The Mother of All Pandemics. Emerg Infect Dis 12(1): 15-22.

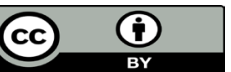

This work is licensed under Creative Commons Attribution 4.0 License

To Submit Your Article Click Here: Submit Article

DOI: $10.32474 /$ SJ0.2020.04.000199

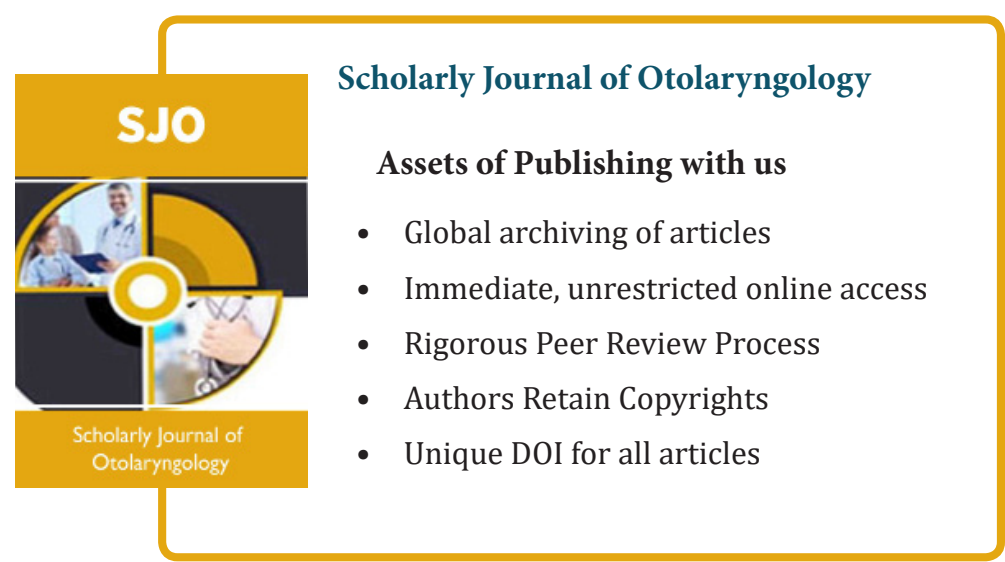

